\title{
Jealousy Levels in Response to Infidelity-Revealing Facebook Messages Depend on Sex, Type of Message and Message Composer: Support for the Evolutionary Psychological Perspective
}

\author{
Michael J. Dunn ${ }^{1} \cdot$ Gemma Billett $^{1}$ \\ Published online: 6 July 2017 \\ (C) The Author(s) 2017. This article is an open access publication
}

Keywords Jealousy · Snooping · Sex differences · Facebook $\cdot$ Social media

\section{Introduction}

Jean-Baptiste Alphonse Karr's epigram 'the more things change, the more they stay the same' encapsulates a belief espoused by evolutionary psychologists when referring to the human condition. This argument that an enduring human nature transcends the vagaries of cultural and technological innovations is also captured by the often quoted description of humans as being 'stone agers in the fast lane' (Eaton et al. 1988). The virtual worlds created by modern technology are fertile grounds to test the explanatory power of such fundamental tenets of evolutionary theory. One such theory, sex differences in jealousy manifestation (Buss 2000; Buss et al. 1992), can be explored by accessing social media such as Facebook and Snapchat (Utz et al. 2015) or by measuring reaction to infidelity-revealing mobile phone messages (Dunn and McLean 2015). There are currently a staggering 1.94 billion active Facebook users worldwide, 1.15 billion of which are active daily and this figure continues to rise relentlessly (Facebook, 5 March 17). Founded in 2004 by Mark Zuckerberg (Key facts 2015), the use of Facebook is ever growing and developing, establishing itself as a staple piece of contemporary everyday life. College students regard presenting themselves as 'in a relationship' on a social network platform, such as Facebook as being a serious romantic relationship milestone (Fox et al. 2013). However, the heightened use of social network platforms including Facebook has been associated with negative romantic relationship outcomes, such as real-world dissatisfaction, both emotional and sexual (Clayton et al. 2013) with a significant rise in the engagement of online infidelity also being noted (Childers and Wysocki 
2011). With online infidelity increasing partner paranoia, inevitably, actions implemented to counteract such behaviours are also on the rise (Beukeboom and Utz 2011). This increased paranoia can help explain the growth of certain mistrusting behaviours, such as 'snooping'.

The modern concept of snooping can be defined as checking one's partner's private possessions and personal communications including private Facebook messages (Derby et al. 2012). Snooping has been found to be a reliable and widely used method of determining infidelity within modern relationships (Waterlow 2015). Currently, most snooping research is predominantly concerned with the exploration and understanding of snooping on a romantic partners mobile phone (Dunn and McLean 2015; Harris 2002; Klette et al. 2014). However, with Facebook playing such a pre-eminent role in modern society, snooping has rapidly moved online as well. With regard to snooping prevalence, it has previously been demonstrated that $66 \%$ of an undergraduate sample admitted to snooping on their partner's private messages without permission and at least another fifth admitting that they were patiently waiting for the appropriate opportunity to snoop (Derby et al. 2012). Snooping is clearly symptomatic of a jealous inclination. The self-perceived security with which online infidelity affords can be exemplified by a survey showing that over a quarter of an adolescent sample had kissed someone they met on social media, even though they knew their love interests were in a romantic relationship with someone else (O'Sullivan and Ronis 2013). Sex differences have also been reported. In a recent study, males reported more engagement in infidelity through meeting someone online than females (Martins et al. 2016). Overall, even a cursory review of the literature suggests that infidelity can be initiated and sustained more easily and is a more accessible activity than ever before.

Of central importance to the current study is to establish whether findings pertaining to jealousy revealed by evolutionary psychologists in previous decades remain in an age where relationship formation and maintenance is often dominated by technology. The general area of sex differences with regard to jealousy in evolutionary psychology has been widely explored with research not only facilitating an understanding of this emotion but also aiding in the conception and implementation of novel methodologies (Buss et al. 1992; Dunn and McLean 2015; Pietrzak et al. 2002). Trivers' parental investment (PI) theory (Trivers 1972) is the most widely cited and influential theory used to explain sex differences across all species. Human females are the choosier sex due to greater parental investment in offspring ( 9 months carrying, labour and lactation). Applying PI theory to sex differences in romantic jealousy, it could be considered an adaptive skill to have heightened awareness of romantic partner's other clandestine romantic inclinations. It is understood for example that male sexual jealousy could act as an awareness or vigilance enhancer to his partner's potential infidelity and therefore could function as an anti-cuckoldry mechanism. For females, emotional jealousy could be seen as an adaptive skill to alert their attention to their romantic mate's resources being diverted elsewhere. These differences between the sexes in romantic jealousy would have proven beneficial for successful reproduction and survival of offspring in the time of our Environment of Evolutionary Adaptiveness (EEA) for both sexes (Geher and Miller 2012; Symons 1980). In addition to the establishment of a significant body of work outlining sex differences in the extent to which types of relationship/ reproductive threat (cuckoldry and loss of parental investment) elicit distress, evolutionary psychologists have also focussed attention on sex differences in who precisely evokes the more jealousy following the discovery of infidelity the 'partner' or the 'rival'? According to Schutzwohl (2008), focus on the intentional object of jealousy is critical for an understanding of the emotion. This makes sense as in order for a defensive strategy to be adaptive, the threat can only be neutralised or diminished by challenging or confronting the person perceived to be the more responsible for jeopardising the relationship. Guided by PI theory once more, from the female perspective, jealousy should be directed towards a same-sex rival as women are the higher investing, more selective and indeed the more valuable sex in human mating and also whilst being the physically weaker sex may be more susceptible to behavioural control, then they should logically be the primary target of jealousy for both men (jealousy eliciting partner) and women (same-sex rival) (Schutzwohl 2008).

Whereas previous studies have implemented the use of paper questionnaire based jealousy eliciting scenarios (Buss et al. 1992; Weiderman and Kendall 1999), the current study incorporated a novel development by presenting participants with imaginary Facebook messages revealing partner infidelity of either an emotional or sexual nature where the discovered message had been either sent (composed by participant's partner) or received (composed by same-sex rival). In support of previous findings, a significant interaction between message type and participant's sex is predicted. More specifically, males would indicate higher distress levels upon the discovery of sexual than emotional infidelity by their partners and also higher distress levels to sexual messages but lower distress to emotional than their female counterparts. For females, the reverse pattern is predicted. Higher distress responses to emotional than to sexual messages and higher distress to emotional but lower distress to sexual responses than those observed in males. It is also predicted that message direction (sent or received) will differentially elicit distress levels depending on participant sex. It is hypothesised that males will experience higher distress upon imagining an infidelity revealing message that is sent (as males have previously been shown to experience jealousy more so towards their partner) rather than 
received (same-sex rival) whereas females will show higher distress to a received (same-sex rival) than a sent (male partner) message as females have been shown previously to focus their jealous sentiment more so on the rival compared to the partner.

\section{Method}

\section{Sample}

An opportunity sample of both male $(n=21)$ and female $(n=23)$ undergraduate students were recruited for this study $M_{\text {age }}=21.3, \mathrm{SD}=4.06$. The only inclusion criterion was participants' confirmed heterosexuality. Participants were recruited on a voluntary basis in return for course credits.

\section{Design}

A mixed design was used consisting of three independent variables (IVs) and one dependent variable (DVs). The first within-subject IV was the content of the message (message type). These imagined messages revealed either emotional or sexual infidelity. The second within-subject IV was whether aforementioned discovered messages were sent or received (message direction). The only between-subject IV was participant sex. The DV was the reported level of distress experienced upon discovery of the imagined, infidelity revealing Facebook message using a linear scale (with 0 being not distressed at all and 10 being very distressed).

\section{Materials}

A PowerPoint presentation of realistic Facebook messages and information on whether the messages were sent or received was presented to participants in sound attenuated laboratory conditions. A concerted effort was made to create discovered messages that were unambiguously either of sexual or emotional content. The emotional messages were edited to be clear than no sexual activity had taken place, and the sexual messages were edited to be clear that only sexual activity had taken place without emotional attachment. Each message contained approximately the same number of words. Participants were asked to rate their distress levels on a linear scale on a separate answer sheet (see Fig. 1. for example of message below).

\section{Procedure}

Participants were presented with the information sheet, consent form and answer sheet and were verbally asked by the researcher to actively engage with the content of the PowerPoint and to take their time. Participants were then left alone and navigated through the slides at their own pace. They were invited to imagine that whilst snooping on their partner's Facebook messenger, they discover messages with the following four scenarios depicting partner infidelity: (1) sexual message received, (2) sexual message sent, (3) emotional message received, (4) emotional message sent and asked to imagine their distress upon discovering them. A total of eight messages were presented randomly (each of the four messages below would be presented twice accompanied by text identifying the composer of the message).

Received (same-sex rival) and sent (participant's partner) sexual messages.

'You must be the best one night f..k I've ever had! Last night was out of this world sexy bum! ;) x'

'Wish I could ride you again like last night babe! I've never cummed like that before! Ha x'

Received (same-sex rival) and sent (participant's partner) emotional messages.

'I honestly don't mind waiting to have sex! Not for a girl (boy when presented to female participants) like you :) You're f.....g perfect baby xx'

'You must be my soulmate! I feel so bloody connected to you, even though we haven't slept together $\mathrm{xxxx}$ '

\section{Results}

The data set included 44 participants ( 21 males, 23 females). All participants were between the ages of 18 and 30 years and of heterosexual orientation (see Fig. 2 below).

Data was analysed using a $2 \times 2 \times 2$ mixed ANOVA with between factors of sex and within factors of message type (sexual/ emotional) and message direction (sent/ received). Analysis showed a significant main effect of sex $\left[F_{1,42}=4.2, p<.001\right.$, partial $\left.\eta^{2}=0.09\right]$, a significant main effect of message type $\left[F_{1,42}=29.4, p<.001\right.$, partial $\left.\eta^{2}=0.41\right]$ but no main effect of message direction $\left[F_{1,42}=0.45, p=.506\right.$, partial $\left.\eta^{2}=0.011\right]$. Significant message type $\times \operatorname{sex}\left[F_{1,42}=32.1, p<.001\right.$, partial $\left.\eta^{2}=0.43\right]$ and message direction $\times$ sex interactions $\left[F_{1,42}=12.3, p<.001\right.$, partial $\left.\eta^{2}=0.29\right]$ were found, but no significant message type $\times$ message direction interaction $\left[F_{1,42}=0.90, p=.457\right.$, partial $\left.\eta^{2}=0.21\right]$ was reported. There was no significant three-way sex $\times$ message type $\times$ message direction interaction $\left[F_{1,42}=0.004, p=.950\right.$, partial $\left.\eta^{2}=0.000\right]$.

Subsequent simple main effect analyses showed a significant difference in distress scores overall between message types for males, with messages of a sexual nature eliciting higher distress scores than emotional 
Fig. 1 Showing an example of an $\mathrm{Fb}$ message shown to participants

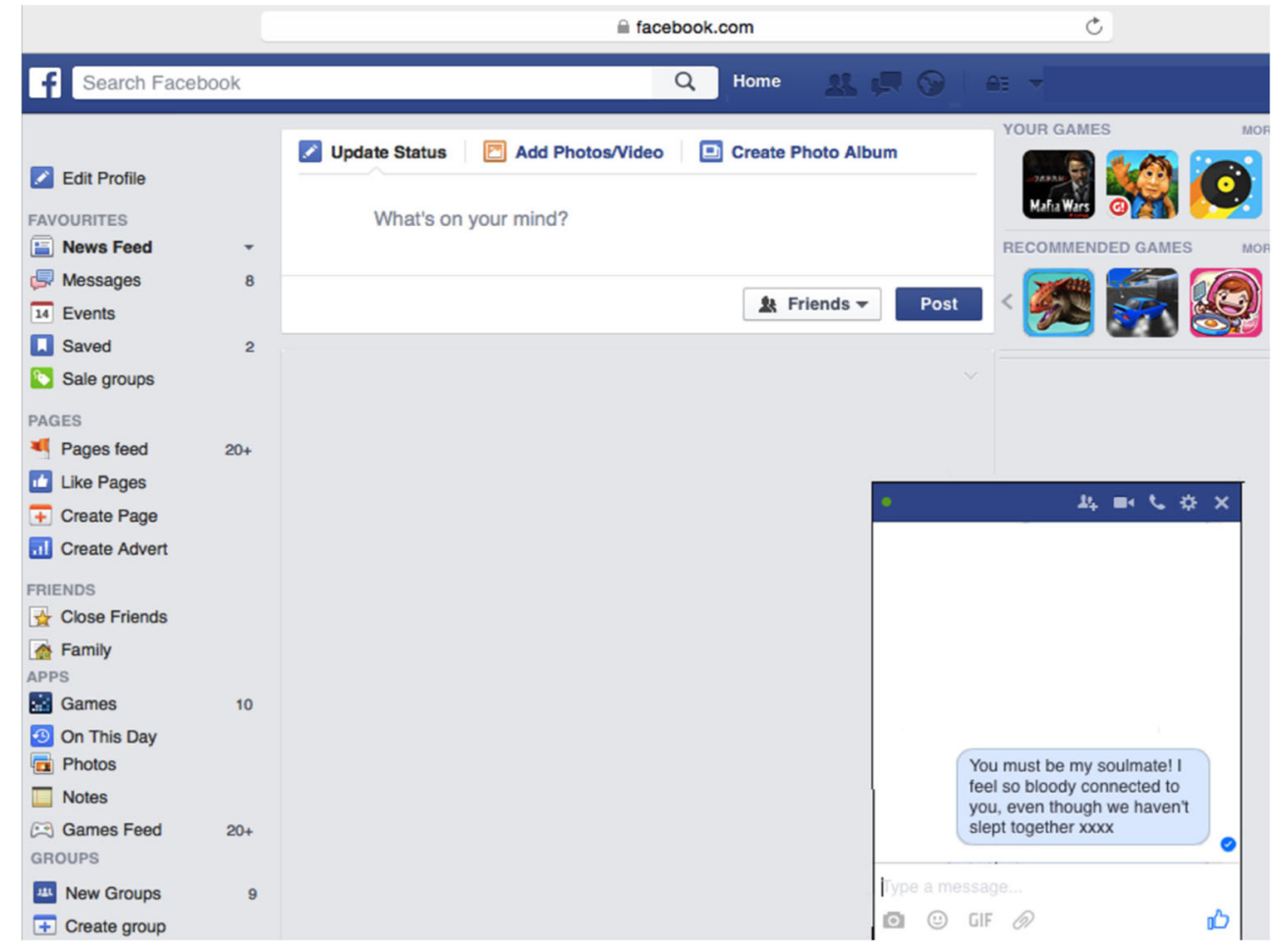

messages $\left[F_{1,42}=58.9, p<.001\right.$, partial $\left.\eta^{2}=0.58\right]$, but no significant difference between message types overall was shown for females $\left[F_{1,42}=0.03, p=.862\right.$, partial $\left.\eta^{2}=0.001\right]$. Overall, females reported higher distress scores for messages of an emotional nature than males $\left[F_{1,42}=18.8, p<.001\right.$, partial $\left.\eta^{2}=0.31\right]$ and males found messages of a sexual nature overall more distressing than females $\left[F_{1,42}=7.6, p=.008\right.$, partial $\left.\eta^{2}=0.15\right]$. For females, there was a significant effect of message direction, with received messages eliciting higher distress scores than sent messages $\left[F_{1,42}=9.2\right.$, $p=.004$, partial $\left.\eta^{2}=0.18\right]$. No differences in distress scores were reported for males between sent and received messages; however, a difference did approximate rejection of the null hypothesis in favour of higher distress scores for sent compared to received $\left[F_{1,42}=3.9\right.$, $p=.055$, partial $\left.\eta^{2}=0.08\right]$. Overall, females reported higher distress scores for received messages than males did overall $\left[F_{1,42}=11.4, p=.002\right.$, partial $\left.\eta^{2}=0.21\right]$. However, there was no significant difference between the sexes for distress scores overall for sent messages $\left[F_{1,42}=0.14, p=.712\right.$, partial $\left.\eta^{2}=0.003\right]$.
Fig. 2 Showing mean distress scores for male and female participants in response to infidelity-revealing sent and received $\mathrm{Fb}$ messages depicting either emotional or sexual infidelity. Values + mean \pm SEM

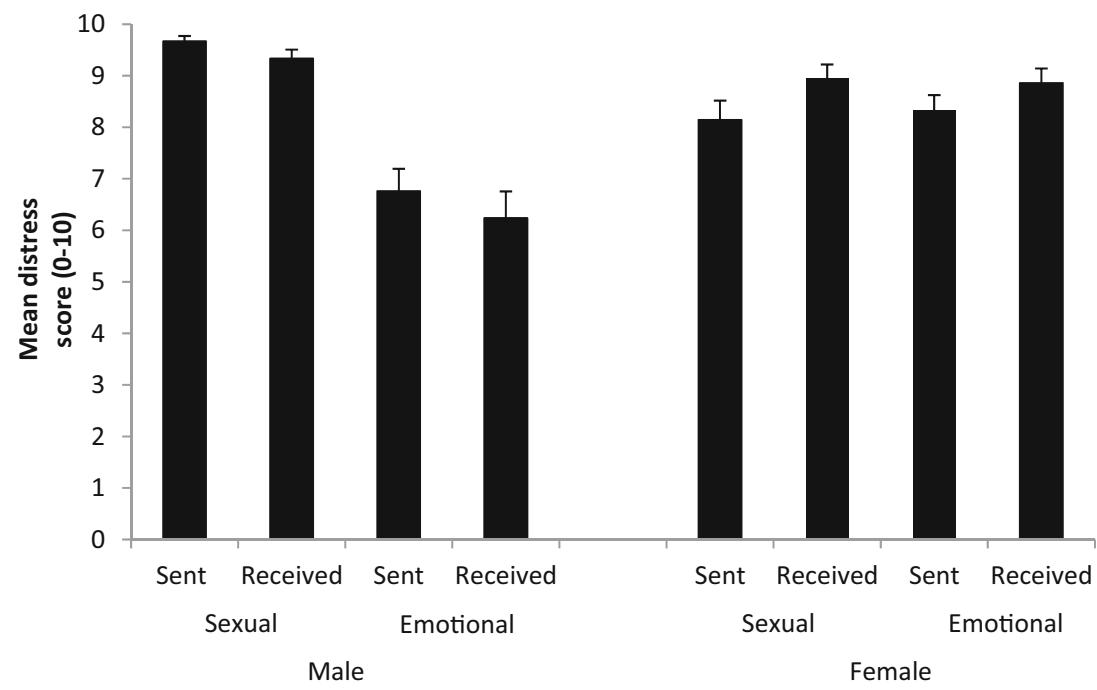




\section{Discussion}

Evolutionary psychologists have for many years documented significant differences between the sexes in how jealousy manifests (Buss et al. 1992, 1999; Sagarin et al. 2012). The current study attempted to support such findings by devising a novel, contemporary, ecologically valid methodological approach whereby participants were presented with imagined sent or received messages discovered on a partner's Facebook account depicting either sexual or emotional contact between their partner or significant other (SO) and a 'rival' or third party. Broadly supportive of evolutionarily informed hypotheses predicting sex differences using both forced-choice and continuous measures in jealousy responses (Buss et al. 1992; Easton et al. 2007; Pietrzak et al. 2002; Sagarin et al. 2003; Schutzwohl 2005; Weiderman and Kendall 1999), significantly higher distress levels were evident in response to sexual than to emotional infidelity-revealing Facebook messages in males and in males compared to females. Using the forced-choice paradigm developed by Buss et al. (1992), Groothof et al. (2009) found significantly that more males than females chose a sexual online liaison (e.g. their partner enacting sexual acts on a webcam) more distressing than their partner engaging in online emotional infidelity with a third party. Unlike in the current study, however, where females did display higher distress than males to emotional Facebook messages, Groothof et al. found no differences between the numbers selecting one over the other as being the more distressing. Whereas previous studies using a variety of methodologies have robustly demonstrated such sex differences in jealousy, this is one of the first to explore sex differences from an evolutionary perspective in jealousy elicitation within the context of social media. With regard to sex differences in cyberjealousy, Dunn and McLean (2015) have shown that males focussed more intently on mobile phone messages that revealed sexual as opposed to emotional infidelity and females were shown to fixate more often and for longer periods than males did to an imagined emotional text message.

In addition to finding support for contemporary online sex differentiation in jealousy type (emotional and sexual), the current study found some supportive evidence for evolutionarily derived theories that predict sex differences in the direction in which jealousy is primarily vented (i.e. towards the cheating partner or the rival). Previous studies have shown that women more than men direct their jealousy towards the rival in a love triangle and men direct their jealousy towards the cheating partner. Thus, women tend to be more so the recipient of jealous inclinations in cases of infidelity (cf. Schutzwohl 2008). In the current study, this was explored by differentiating between sent and received Facebook messages. Women were significantly more distressed when imagining the discovery of received than sent messages and were also significantly more distressed than males when imagining discovering a received infidelity-relating message irrespective of message type. These findings are suggestive of a tendency for women to apportion blame to the female rival rather than the cheating male partner in cases of infidelity (Buss 2000). As for males, even though no statistically significant differences were reported in imagined distress levels upon discovering a sent as opposed to a received Facebook message, a difference (in the direction of higher sent than received) did approximate rejection of the null hypothesis. Sent messages in the case of male participants would of course once again suggest blame is directed to the cheating female partner as opposed to in this case a rival male (Buss 2000). No differences were reported between the sexes when comparing distress levels for sent messages, however.

Of the eight hypotheses tested, five were confirmed, one partially supported and only two rejected. When considering the data, one could speculate that support would have been forthcoming had the data not been at ceiling. Male participants more generally indicated a maximum distress score (10) in response to sexual messages and proportionately more to sexual messages that were sent by their partner. Arguably, the ceiling effects observed in the current study exemplify the 'real-world' nature of the imagined scenarios in how evocative they were. Participants clearly did not experience difficulties in imagining the infidelityrevealing messages. Schutzwohl (2005) showed that sex differences in cues that elicit jealousy are not evident until what he regard as the 'first threshold' of jealousy after which the sexual/ emotional distinction becomes more pronounced. The severity of the response in the current study suggests that the messages were sufficiently realistic to trigger what Schutzwohl regard as the 'second threshold' where jealous feelings become intolerable. Younger adults have been shown previously to experience higher distress levels to infidelity cues generally, especially those of a sexual nature (Harris 2002).

In devising the methodology of the current study, every effort was made to improve the ecological validity of the topic under investigation by contextualising jealousy within a modern technology framework. That being said, controversies originating in previous related studies were evident also in the current study. For example the current study in addition to employing a continuous measure analysis utilised a simple effect analysis to test a number of specific directional hypotheses. This approach has been criticised by authors who have presented a compelling rationale for the employment of statistical analyses relating to sex differences in jealousy that focus exclusively on the interaction (cf. Sagarin 2005; Edlund and Sagarin 2009; Sagarin et al. 2012). The current study also prides itself on the efforts employed to render the types of infidelity (sexual and emotional) conveyed by the messages mutually exclusive in line with previous studies (cf. Buss et al. 1999 for an approach to operationalizing exclusivity of each type of infidelity). The difficulty in achieving this end is exemplified by the message

'You must be my soulmate! I feel so bloody connected to you, even though we haven't slept together yet $\mathrm{xxxx}$ '. 
Even here despite the fact that there is clarity regarding the fact that sexual infidelity has not yet occurred, it still may imply that it is likely to occur in the future. Future studies need to address these concerns regarding mutual exclusivity and the manner in which messages or scenarios are presented to participants. For example future studies may benefit by adopting a between-subject design whereby different groups of participants are presented with one carefully crafted message type alone in order to facilitate message disambiguity.

Understanding the mechanisms underlying jealousy is important as partner infidelity whether real or suspected has been implicated repeatedly in cases of domestic abuse and violence. Homicides are clearly the tip of the iceberg in terms of the misery attributed to sexual and emotional jealousy. According to Buss (2014, p. 313), male sexual jealousy 'appears to be at the root of women killing their husbands, as well as at the root of the more common case of men killing their wives'. In an early study focussing on spousal homicides in Baltimore, 25 of the 36 identified were shown to be related to partner jealousy (Guttmacher 1955). It would appear that jealousy-evoked violence committed against women by men has been a relatively common occurrence and is cross-culturally and historically invariant in its prevalence (Daly and Wilson 1988). Consequences of cyber jealousy have emerged online also, and it has been suggested that social networking sites such as Facebook can actively intensify pre-disposed jealous impulses in romantic relationships and create new suspicions (Muise et al. 2009). Brem et al. (2015) have argued that Facebook is an ideal environment for the adoption of mate-retention tactics with clear implications for intimate partner violence. Focussing an evolutionary lens on internet behaviour has already began (cf. Piazza and Bering 2009); however, applying an evolutionary perspective to understanding the manifestation of jealous behaviour and how infidelity-related anger can trigger partner dissolution and domestic abuse may help counteract inevitable rises in such behaviours in an age where clandestine extra-marital relationships are facilitated by modern forms of media technology.

\section{Compliance with Ethical Standards}

Funding This research did not receive any specific grant from funding agencies in the public, commercial or not-for-profit sectors.

Conflict of Interest The authors declare that they have no conflict of interest.

Open Access This article is distributed under the terms of the Creative Commons Attribution 4.0 International License (http:// creativecommons.org/licenses/by/4.0/), which permits unrestricted use, distribution, and reproduction in any medium, provided you give appropriate credit to the original author(s) and the source, provide a link to the Creative Commons license, and indicate if changes were made.

\section{References}

Beukeboom, C. J., \& Utz, S. (2011). The role of social network sites in romantic relationships: effects on jealousy and relationship happiness. Journal of Computer-Mediated Communication, 16(4), 511-527.

Brem, M. J., Spiller, L. C., \& Vandehey, M. D. (2015). Online materetention tactics on Facebook are associated with relationship aggression. Journal of Interpersonal Violence, 30, 2831-2850.

Buss, D. M. (2000). The dangerous passion: Why jealousy is as necessary as love and sex. New York: Free Press.

Buss, D. M. (2014). Evolutionary psychology. The science of the mind (4th ed.). England: Pearson education, Inc..

Buss, D. M., Larsen, R. J., Westen, D., \& Semmelroth, J. (1992). Sex differences in jealousy: evolution, physiology and psychology. Psychological Science, 3(4), 251-255.

Buss, D. M., Shackelford, T. K., Kirkpatrick, L. A., Choe, J. C., Lim, H. K., Hasegawa, M., et al. (1999). Jealousy and the nature of beliefs about infidelity: tests of competing hypotheses about sex differences in the United States, Korea, and Japan. Personal Relationships, 6, $125-150$.

Childers, C., \& Wysocki, D. (2011). Let my fingers do the talking. Sexting and Infidelity in Cyberspace, 15(3), 217-239.

Clayton, R. B., Nagurney, A., \& Smith, J. R. (2013). Cheating, breakup, and divorce: is Facebook use to blame? Cyberpsychology, Behavior and Social Networking, 16(10), 717-720.

Daly, M., \& Wilson, M. (1988). Evolutionary social psychology and family violence. Science, 242, 519-524.

Derby, K., Knox, D., \& Easterling, B. (2012). Snooping in romantic relationships. College Student Journal, 46, 333-343.

Dunn, M., \& McLean, H. (2015). Jealousy induced sex differences in eye gaze directed at either emotional or sexual infidelity related mobile phone messages. Cyberpsychology, Behavior, and Social Networking, 18, 37-40.

Easton, J. A., Schipper, L. D., \& Shackelford, T. D. (2007). Morbid jealousy from an evolutionary psychological perspective. Evolution and Human Behavior, 28, 399-402.

Eaton, S. B., Konner, M., \& Shostak, M. (1988). Stone agers in the fast lane: chronic degenerative diseases in evolutionary perspective. American Journal of Medicine, 84, 739-749.

Edlund, J. E., \& Sagarin, B. J. (2009). Sex differences in jealousy: misinterpretation of non-significant results as refuting the theory. Personal Relationships, 16, 67-78.

Fox, J., Warber, K. M., \& Makstaller, D. C. (2013). The role of Facebook in romantic relationship development: an exploration of Knapp's relational stage model. Journal of Social and Personal Relationships, 30(6), 771-794.

Geher, G., \& Miller, G. (2012). Mating intelligence: Sex, relationships, and the mind's reproductive system. New York: Psychology Press.

Groothof, H. A., Dijkstra, P., \& Barelds, D. P. (2009). Sex differences in jealousy: the case of internet infidelity. Journal of Social and Personal Relationships, 26(8), 1119-1129.

Guttmacher, M. S. (1955). Criminal responsibility in certain homicide cases involving family members. In P. H. Hoch \& J. Zubin (Eds.), Psychiatry and the law. New York: Grune and Stratton.

Harris, C. R. (2002). Sexual and romantic jealousy in heterosexual and homosexual adults. Psychological Science, 13, 7-12.

Key facts. (2015). From http://newsroom.fb.com/company-info/.

Klette, B., Hallford, D. J., \& Mellor, D. J. (2014). Sexting prevalence and correlates: a systematic literature review. Clinical Psychology Review, 34, 44-53.

Martins, A., Pereira, M., Andrade, R., Dattilio, F. M., Narciso, I., \& Canavarro, M. C. (2016). Infidelity in dating relationships: genderspecific correlates of face-to-face and online extradyadic involvement. Archives of Sexual Behavior, 45, 1-13. 
Muise, A., Christofides, E., \& Desmarais, S. (2009). More information than you ever wanted: does Facebook bring out the green-eyed monster of jealousy? Cyberpsychology and Behavior, 12(4), 441-444.

O'Sullivan, L. F., \& Ronis, S. T. (2013). Virtual cheating hearts: extradyadic and poaching interactions among adolescents with links to online sexual activity. Journal of Behavioural Science, 45(3), 175-184.

Piazza, J., \& Bering, J. M. (2009). Evolutionary cyber psychology: applying an evolutionary framework to internet behaviour. Computers in Human Behavior, 25(6), 1258-1269.

Pietrzak, R. H., Laird, J. D., Stevens, D. A., \& Thompson, N. S. (2002). Sex differences in human jealousy. A coordinated study of forcedchoice, continuous rating-scale, and physiological responses on the same subjects. Evolution and Human Behavior, 23, 83-94.

Sagarin, B. J. (2005). Reconsidering evolved sex differences in jealousy: comment on Harris (2003). Personality and Social Psychology Review, 9, 62-75.

Sagarin, B. J., Becker, D. V., Guadagno, R. E., Nicastle, L. D., \& Millevoi, A. (2003). Sex differences (and similarities) in jealousy. The moderating influence of infidelity experience and sexual orientation of the infidelity. Evolution and Human Behavior, 24, 17-23.

Sagarin, B. J., Martin, A. L., Coutinho, S. A., Edlund, J. E., Patel, L., Skowronski, J. L., \& Zengel, B. (2012). Sex differences in jealousy: a meta-analytic examination. Evolution and Human Behavior, 33, 595-614.

Schutzwohl, A. (2005). Sex differences in jealousy: the processing of cues to infidelity. Evolution and Human Behaviour, 26, 288-299.

Schutzwohl, A. (2008). The intentional object of romantic jealousy. Evolution and Human Behaviour, 29, 92-99.

Symons, D. (1980). The evolution of human sexuality revisited. The Behavioral and Brain Sciences, 3(2), 203-214.

Trivers, R. (1972). Parental investment and sexual selection. Biological Laboratories, 136, 179.

Utz, S., Muscanell, N., \& Khalid, C. (2015). Snapchat elicits more jealousy than Facebook: a comparison of Snapchat and Facebook use. Cyberpsychology, Behavior and Social Networking, 18, 141-146.

Waterlow, L. (2015). Checking partner's mobile phone is most common way affairs are exposed. Retrieved October 28, 2015 from Daily mail online: http://www.dailymail.co.uk/femail/article-2268169/ Dail-I-infidelity-Checking-partners-mobile-phone-common-wayaffairs-exposed.html.

Weiderman, M. W., \& Kendall, E. (1999). Evolution, sex and jealousy: Investigation with a sample from Sweden. Evolution and Human Behavior, 20, 121-128. 